\title{
Using Social Messenger in Knowledge Sharing Practice: A Literature Review
}

\author{
Isnaeni Nurrohmah ${ }^{1}$, Dana I. Sensuse ${ }^{2}$ \\ ${ }^{1,2}$ Faculty of Computer Science, Universitas Indonesia \\ 1'isnaeni.nurrohmah61@ui.ac.id
}

\begin{abstract}
The use of social messenger is affecting the interaction and communication between people. This article identifies the use of social messenger in knowledge sharing practice. First, we identify the used of social messenger to support daily life, then we identify the knowledge sharing activities using social media, and finally we identify the negative effects of using social messenger to support knowledge sharing practice. The term social messenger that we used in this article is social networking that has instant messaging feature, such as WhatsApp, Facebook, MSN, etc. To identify the problems, we conducted systematic literature review in ScienceDirect and selected 14 articles from several publications. The data of articles were extracted into several criteria and synthesis in order to answer the problems. The result of this study is social messenger support communication, file sharing, and content creation. The main knowledge sharing activity is discussion for sharing tacit knowledge and file sharing for sharing explicit knowledge. However, we found that privacy; time, digital divide, ethical issue, and disruptive relationship are challenge of using social messenger in knowledge sharing practice.
\end{abstract}

Keywords: knowledge sharing, social messenger, discussion, files sharing, literature review.

\section{Introduction}

Knowledge Management has become an essential in this modern era. One of the most important process of knowledge management is knowledge sharing [1]. Knowledge sharing is a key process in knowledge management that delivers knowledge where it is needed from one person to another [1], [2]. The more effective knowledge sharing process the greater effect in knowledge management in order to increase competitive advantage in an organization [3]. In an organization, knowledge sharing becomes more important because it is a challenge for organization to create knowledge sharing friendly environment.

In knowledge sharing process, individual knowledge sharing is affected by motivation and factors that involves in the individual behavior [3]. However, the willingness for individual to share and transfer their knowledge to other people is a major issue in knowledge sharing process [3]. So, there are a lot of researchers that investigate knowledge sharing process.

Knowledge sharing process can occur in organization, family, friends, or casually among people [4]. In an organization, knowledge are deliver in a formal way, however, in common people interaction (such as family or friends) knowledge are deliver in informal ways. Some people prefer to deliver and share knowledge in informal or casual ways.

In the modern era, communication technology can facilitate and support knowledge sharing process [4]. Such technologies that can be used to share, transfer, or exchange knowledge define as knowledge sharing system. Social Network System (SNS) is a popular ways to support knowledge sharing, interaction, and exchanging experience [4], [5]. SNS can facilitate knowledge sharing in informal or casual way because there are no particular rules in communication process. The examples of popular SNS are Facebook, WhatsApp, Line, YouTube, etc.

Then, users need a faster and responsive SNS in order to perceive their need to quick communication. Social messenger comes as adaptation of SNS that deliver an instant messaging system. Basically, social messenger are used as media for communication. However, some messengers provides advanced features such as call, file sharing, photos sharing, etc. In this paper, we will discuss about knowledge sharing practice using SNS that has social messenger features such as instant messenger. 
The purpose of this paper is to identify the knowledge sharing practice among people using social messenger. The identification was conducted using systematic literature review from similar previous studies. To direct the systematic literature review process, we provided three research questions:

$\mathrm{R} 1:$ How people used social messenger to support daily life?

R2: How knowledge sharing activities using social messenger?

R3: What are the negative effects of using social messenger to support knowledge sharing process?

\section{Method}

This article will create a systematic literature review about knowledge sharing behavior using social messenger application. Systematic literature review (SLR) is one of the research methods that constructed from identifying, evaluating, and interpreting process of the previous research studies about particular topic [6]. This paper were modified from previous SLR research by Zahedi et.al [6] that conducting three steps: defining review protocol, conducting review, and reporting review. The review protocol that we used to answer the research question contains search strategy, inclusion and exclusion criteria, study selection, study quality assessment, and data extraction. Here we discuss each protocol review.

\subsection{Search Strategy}

The most important protocol in SLR is defining search strategy. This protocol is used to create adequate combination of keywords and data resource in order to retrieve appropriate studies. The strategy provides retrieval process for selecting initial articles.

The first strategy is formulation of search string. Search string consists of combination of keywords that is used to retrieve articles in data sources. As our purpose of this letter, we choose to use the combination of "knowledge sharing" and "social messenger" as the keywords. However, some studies used different word to express "knowledge sharing" and "social messenger", so we used the synonym of both phrase. Table I show the structure of search string that we used in this SLR:

TABLE I: Search string strategy

\begin{tabular}{ll}
\hline \hline \multicolumn{1}{c}{ Context } & \multicolumn{1}{c}{ Search String Strategy } \\
\hline Knowledge Sharing & Knowledge sharing, knowledge transfer, knowledge exchange, \\
& knowledge management \\
Social messenger & Messenger, social messenger, chatting application, WhatsApp, Line, \\
& Facebook messenger, \\
\hline \hline
\end{tabular}

Afterwards, the final string search that we applied in the title, abstract, and keywords as:

("knowledge sharing" OR "knowledge transfer" OR "knowledge exchange" OR "knowledge distribution" OR "sharing knowledge" OR "transfer knowledge" OR "exchange knowledge") AND

("WhatsApp" OR "Line" OR "Social Messanger" OR "instant messenger" OR "chatting application" OR "facebook messenger")

The search string was run on ScienceDirect (www.sciencedirect.com) digital indexing system. We chose ScienceDirect because it provides over 3.800 journals with millions of publications from any different educational background [7]. In addition, our institution has direct access so we can easily retrieve the articles. We also try to retrieve articles from others digital library, such as IEEEXplore, Springer, Scopus, but those did not gives us adequate results. There are very limited articles about knowledge management in IEEEXplore. In addition, we have no support to access full articles in Springer and Scopus. So, ScienceDirect were sufficient to provide the articles. Table II shows the detail of the article retrieval process. We select create boundary of the search string running process based on year of publication, type of publication, section of keywords running, and subject area.

TABLE II: Detail of Retrieval Process

\begin{tabular}{ll}
\hline \hline Digital Library & ScienceDirect \\
\hline Years: & $2013-2016$ \\
Type: & Journal/Conference Paper \\
Section & Title/Abstract/Keywords \\
Subject Area: & Computer Science, Information Management, Psychology \\
Language: & English \\
Date of retrieval: & September 18, 2016 \\
\hline \hline
\end{tabular}




\subsection{Inclusion and exclusion criteria}

From the retrieval process, we were not using all of the articles. We selected relevant articles based that can be used to fulfill the purpose of this study. Basically, inclusion and exclusion criteria are used to obtain relevant studies about knowledge sharing using social messenger. We apply the inclusion and exclusion criteria to all retrieved data from the digital library. The inclusion and exclusion criteria for this study are:

- Full articles from journal and conference paper were included in this SLR and we exclude if the articles were partial or not full.

- Articles from secondary data such as book were excluded from this SLR.

- Only final corrected articles were used in this SLR. The articles that were in corrected proof were excluded in this review.

- Both empirical and theoretical were included in this literature review.

- There is no duplication articles if there is duplication only choose one article and discard others.

\subsection{Study Selection}

The process of articles' selection was conducted in 5 steps. First, we retrieve articles from ScienceDirect using search string strategy and we receive 268 articles. The articles then screen based on the title, abstract, and keyword to find adequate articles which perform study about social networking that has instant messaging features. Then, we excluded the in corrected proof articles and included only final corrected articles. This stage provides 68 articles. The duplicates articles were removed, so we removed 2 articles from the result. Finally, we read the full paper to find the appropriate study that can support this study and we exclude the similar study so finally, we selected 14 main articles.

\subsection{Data extraction and synthesis}

Data extraction aims to extract the selected articles from SLR. The extraction process is to identify the information needed in order to answer the research questions. The extraction items that we used to analyze every article were shown in the Table III. The result of the extracted information was placed into table so we can easily compare the knowledge sharing practice using social messenger.

Later, we conduct a synthesis to the extracted data to facilitate discussion and answering the research question. To synthesis the data from the extracted articles, we separate the discussion into two parts consists of (a) demographic and contextual attributes and (b) research question discussion. The demographic and context discussion were analyzed using qualitative method and produce. The research question discussion answered the three research question based on the analysis of the selected articles.

\section{Demographic and Contextual}

Based on the data extraction criteria, we have extracted 14 articles. Appendix A. contains the result of data extraction. In this section, we discuss demographic and contextual based on data extraction result.

\subsection{Distributions}

The result of the article selection is selecting 14 articles from the digital library that discuss about using social messenger to sharing knowledge. From the selected articles, we found that the articles were published in 2013, 2014, 2015, and 2016. We select the most recent articles to find the most update finding as shown on Table III. Most of selected articles are published in 2016 (9 articles), in 2015 and 2014 (2 articles each), and in 2013 (1 article) .

Based on Table III, we extract the articles based on the context which studies were conducted. We identify that the articles discuss about education, young people, health, project management, and social activities Most articles discuss about knowledge sharing in education, such as how students interact with other students or teachers and use social messenger to support education. Knowledge sharing in young people discuss about how young people utilize social messenger in hedonic activity, such as photos sharing, chatting, news sharing etc [8][10]. Knowledge sharing in health discuss about using social messenger to sharing photos for pre-clinical examination conducted by dentist [11]. Meanwhile, an articles describe about how software development team share their knowledge using social messenger [12]. Another context that discuss by selected article is knowledge sharing activities in non-government organization (NGO) using social messenger [13]. Finally, using social messenger to sharing knowledge were implement by many aspects such as education, health, etc. 
TABLE III: The selected articles

\begin{tabular}{|c|c|c|c|c|c|c|c|c|}
\hline \# & Title & Author & Year & Publication & $\begin{array}{c}\text { Research } \\
\text { Methods }\end{array}$ & Context & Tool & $\begin{array}{c}K S \\
\text { Practice } \\
\end{array}$ \\
\hline $\mathrm{P} 1$ & $\begin{array}{l}\text { Exploring the Use and the } \\
\text { Impacts of Social Media } \\
\text { on Teaching and Learning } \\
\text { Science in Saudi [14] }\end{array}$ & $\begin{array}{l}\text { Abdullah, } \\
\text { Saleh }\end{array}$ & 2015 & $\begin{array}{l}\text { Procedia- } \\
\text { Social and } \\
\text { Behavioral } \\
\text { Science }\end{array}$ & $\begin{array}{l}\text { Case Study, } \\
\text { Quantitative, } \\
\text { Questionnaire }\end{array}$ & $\begin{array}{l}\text { KS in } \\
\text { education }\end{array}$ & WhatsApp & $\begin{array}{l}\text { Share ideas } \\
\text { with } \\
\text { classmates } \\
\& \text { teachers, } \\
\text { Access } \\
\text { content ad } \\
\text { resources }\end{array}$ \\
\hline P2 & $\begin{array}{l}\text { Social Media Intelligence } \\
\text { Quotient ( SMIQ ) Among } \\
\text { Graduates : Knowledge } \\
\text { Gathering from Focus } \\
\text { Group with Graduates } \\
\text { [15] }\end{array}$ & $\begin{array}{l}\text { Ain, } \\
\text { Nadhrathul } \\
\text { Musa, } \\
\text { Rosidah } \\
\text { Azreen, } \\
\text { Ainul }\end{array}$ & 2016 & $\begin{array}{l}\text { Procedia - } \\
\text { Economics } \\
\text { and } \\
\text { Finance }\end{array}$ & $\begin{array}{l}\text { Case Study, } \\
\text { Qualitative, } \\
\text { Focus Group } \\
\text { Discussion }\end{array}$ & $\begin{array}{l}\text { KS in } \\
\text { education }\end{array}$ & Facebook & $\begin{array}{l}\text { Sharing } \\
\text { opinion and } \\
\text { knowledge }\end{array}$ \\
\hline P3 & $\begin{array}{l}\text { Convenience or } \\
\text { Nuisance ?: The } \\
\text { 'WhatsApp' Dilemma [9] }\end{array}$ & $\begin{array}{l}\text { Dayani, } \\
\text { Annie } \\
\text { Ariff, } \\
\text { Syamimi }\end{array}$ & 2014 & $\begin{array}{l}\text { Procedia- } \\
\text { Social and } \\
\text { Behavioral } \\
\text { Science }\end{array}$ & $\begin{array}{l}\text { Case Study, } \\
\text { Quantitative, } \\
\text { Questionnaire }\end{array}$ & $\begin{array}{l}\text { KS in } \\
\text { young } \\
\text { people }\end{array}$ & WhatsApp & $\begin{array}{l}\text { Discussing } \\
\text { and sharing } \\
\text { information }\end{array}$ \\
\hline P4 & $\begin{array}{l}\text { Social networking, } \\
\text { knowledge sharing, and } \\
\text { student learning: The case } \\
\text { of university students [4] }\end{array}$ & $\begin{array}{l}\text { Eid, Mustafa } \\
\text { I M } \\
\text { Al-jabri, } \\
\text { Ibrahim M }\end{array}$ & 2016 & $\begin{array}{l}\text { Journal of } \\
\text { Computer } \\
\text { and } \\
\text { Education }\end{array}$ & $\begin{array}{l}\text { Case Study, } \\
\text { Quantitative, } \\
\text { Questionnaire }\end{array}$ & $\begin{array}{l}\text { KS in } \\
\text { education }\end{array}$ & $\begin{array}{l}\text { WhatsApp, } \\
\text { Facebook }\end{array}$ & $\begin{array}{l}\text { Chatting } \\
\text { and } \\
\text { Discussion, } \\
\text { File sharing }\end{array}$ \\
\hline P5 & $\begin{array}{l}\text { To use or not to use? } \\
\text { Social media in higher } \\
\text { education in developing } \\
\text { countries [16] }\end{array}$ & $\begin{array}{l}\text { Elnasr, Abu } \\
\text { Sobaih, E } \\
\text { Moustafa, } \\
\text { Mohamed A } \\
\text { Ghandforous } \\
\text { h, Parvis }\end{array}$ & 2016 & $\begin{array}{l}\text { Journal of } \\
\text { Computers } \\
\text { in Human } \\
\text { Behavior }\end{array}$ & $\begin{array}{l}\text { Case Study, } \\
\text { Quantitative, } \\
\text { Questionnaire }\end{array}$ & $\begin{array}{l}\text { KS in } \\
\text { education }\end{array}$ & $\begin{array}{l}\text { WhatsApp, } \\
\text { Facebook }\end{array}$ & $\begin{array}{l}\text { Discussion, } \\
\text { sharing } \\
\text { information }\end{array}$ \\
\hline P6 & $\begin{array}{l}\text { The effects of social } \\
\text { media on students } \\
\text { behaviors ; Facebook as a } \\
\text { case study [17] }\end{array}$ & $\begin{array}{l}\text { Kaya, } \\
\text { Tugberk } \\
\text { Bicen, } \\
\text { Huseyin }\end{array}$ & 2016 & $\begin{array}{l}\text { Journal of } \\
\text { Computers } \\
\text { and Human } \\
\text { Behavior }\end{array}$ & $\begin{array}{l}\text { Case Study, } \\
\text { Quantitative, } \\
\text { Questionnaire }\end{array}$ & $\begin{array}{l}\text { KS in } \\
\text { education }\end{array}$ & Facebook & $\begin{array}{l}\text { File/inform } \\
\text { ation } \\
\text { sharing }\end{array}$ \\
\hline P7 & $\begin{array}{l}\text { Consuming, sharing, and } \\
\text { creating content : How } \\
\text { young students use new } \\
\text { social media in and } \\
\text { outside school [5] }\end{array}$ & $\begin{array}{l}\text { Lu, Jingyan } \\
\text { Hao, Qiang } \\
\text { Jing, } \\
\text { Mengguo }\end{array}$ & 2016 & $\begin{array}{l}\text { Journal of } \\
\text { Computers } \\
\text { and Human } \\
\text { Behavior }\end{array}$ & $\begin{array}{l}\text { Case Study, } \\
\text { Quantitative, } \\
\text { Questionnaire }\end{array}$ & $\begin{array}{l}\text { KS in } \\
\text { education }\end{array}$ & Facebook & $\begin{array}{l}\text { Content } \\
\text { sharing }\end{array}$ \\
\hline
\end{tabular}

As we discuss about social messenger, there are a lot of social messenger application that are used by most people. In data extraction process, we classified the articles based on the social messenger tool that mainly discuss in each articles. In this literature review, we extracted knowledge sharing that provides instant messaging features, such as WhatsApp, Facebook, Line, etc. Facebook and WhatsApp are the most popular application that is used in the selected study. WhatsApp is widely used because it provides real-time communication with the ease of information and file sharing features [8], [9]. Facebook is more general because it can be used in both personal computer and mobile phone and it gives more communication tools such as messenger, news feed, group, etc. [17].

There are many types and action to conduct knowledge sharing practice using social messenger which allows user to share their knowledge. Both tacit and explicit knowledge can be shared through social networking, using different kinds of practices. From the selected articles, we identify that knowledge sharing practice using social messenger. Table V show the knowledge sharing practice using tools mention in section $\mathrm{B}$. The column purpose identifies the purpose of using the tools and the column KS Practice identifies the knowledge sharing practice using the tools.

\section{Result and Discussion}

This section answers the research questions that we describe in the beginning of this article. The questions which follows by brief discussion for each question are answered based on the result of systematic literature review. 


\subsection{How people used social messenger to support daily life?}

Social messenger are widely used as daily life supporter. There are several kinds of social messenger that used by most people, such as WhatsApp [8], [9], [11], LINE, Facebook Messenger [17], Google Hangout, and Kakao Talk. Most of people use social messenger to interact and communicate with other people [4]. From the selected articles, we identify that social messenger were used to support daily life activities; communication, file/content sharing, content creation, and discussion. In this section, we will discuss the use of social messenger to support those daily activities.

\section{Communication}

Social messenger comes from the term of Social Networking System (SNS). The main purpose of SNS is to promote interaction and communication among the user [4]. Social messenger adopt the SNS feature but it allows the user to communicate quickly with other user through instant messaging [14]. As it adopt from SNS, it also benefit to enhance communication network to employ quick access to information. There are two types of communication using social messenger; (1) One-to-one which allows user to communicate privately with another user and (2) many-to-many which allows user to directly communicate with some people. Usually, this type of communication is implemented by social messenger using such a feature called 'group' [17].

Most articles discuss about the effect of social messenger in education, such as school and university. In education, social messenger can be used by the teacher to communicate and engage the students that enrolled in their course [16]. The communication between students and their teacher enhance interaction and increase students motivation through the course [14]. This activity has impact on knowledge sharing and learning performance [4].

\section{File/Content Sharing}

Besides used as communication, social messenger is also used as file and content sharing between its users. The examples of files and contents that transferred between them are pictures, videos, voices, news, lecturers materials, study related matters [9][11] [17][14] [16]. From the review of the articles, the activities of file and content sharing among social messenger's users were triggered from entertainment purpose [16], health purpose [11], and educational purpose [5]Kaya \& Bicen, 2016).

Most articles describe that social messenger facilitate to share photos, videos, news, or information for hedonic and entertainment purposes [4], [9], [16]. These purposes make users enjoy interacting with the system and other users. They also can get information about new event or product from the advertisement that usually used social messenger to disseminate it.

In education, the file sharing were employed between students-to-students [9] and teachers-to-students [16]. SNS facilitate university students to share files/content related to academic matters such as lecture notes, assignment information, project tasks, procedural videos, etc. [4]. In addition, lecturer also can share lecturer academic documents through social messenger [16].

\section{Content Creation}

Not only low-level activity of communication and sharing, social messenger also provide a high-level benefit of content creating. This activity is more complicated than consuming and sharing knowledge because it is stimulate certain patterns of users ideas and opinion [5]. Some social messenger create content as a result of interactive social environment activities [16]. Social messenger can engage users in content creating activities and stimulate content creating behavior of the users in which plays important roles that requires higher level of intellectual effort [5]. There are several activities of content creation using social messenger, such as micro status, smashing content online, short video broadcast, etc. Content creation may follows by social interaction [9].

In education, content creation do not has an impact on knowledge sharing and learning performance [4]. It is because social messenger are significant in content creating matters outside school. While content creation has a relationship with self-regulation in learning performance [5].

\subsection{How knowledge sharing activities using social messenger?}

Most articles discuss that the main activities of using social messenger are communication and file sharing. These activities related to knowledge sharing which allows user to interact with other users. The interaction purposes to share their knowledge for both tacit (through discussion) and explicit (through file sharing). 


\section{Discussion}

The most common knowledge sharing activities using social messenger is discussion [13] [14] [18]. The discussion in some context is facilitated by social networking in by transferring tacit knowledge from one user to others. The tacit knowledge are transferred by codified the knowledge into words (messages) then the owner of its knowledge transferred it to other users. In most practice, the knowledge was deliver in informal or casual ways through social messenger [5].

In software project development, they are facilitated by social messenger in sharing know where and know whom information to other member [19]. The discussion change the role of face-to-face meetings into group discussion in effective way [19]. Discussion as part of knowledge sharing activities in software project development which an empirical research find that knowledge sharing has positive impact on team members' performance [12].

Meanwhile, in cyber-volunteering context, they discuss information with other member or with public audience about certain problem in order to solved it quickly and effectively [13]. Discussion is part of knowledge sharing activities within Non-Government Organization which share and discuss about programs or activities [13]. The use of social messenger is because some volunteers can't join in offline discussions.

In education, social messenger are using in discussion for study related matters [9] because it is the convenience in sharing, quick retrieval and transfer. Not only student-to-student, social messenger can also use to discuss learning materials between students and teachers [14]. The students use social messenger to discuss about concept and ideas and exchanging their idea with their friends [4].

\section{File sharing}

The other knowledge sharing practice using social messenger are file sharing. Most social messenger applications such as WhatsApp and Facebook Messengers, have feature(s) to sharing content or file, such as pictures, files, audios, videos, etc. [11] [16]. This feature can support communication and discussions between social messengers' users by exchanging supporting files. The user-generated file sharing transfers files or content that contains explicit knowledge such as file documents, pictures, etc.

Some organization used file sharing feature in social messenger to sharing explicit knowledges. In health, social messenger can be used to transfer digital content of clinical image of the patients which will be examine by the expert through WhatsApp [11]. In education, file sharing help students and teachers transfer academic materials such as lecture notes, assignment information, instructional videos, etc. [4]. An empirical study concluded that the file sharing activities has an impact on knowledge sharing [4].

\subsection{What are the negative effects in using social messenger to support knowledge sharing process?}

As we described above, social messenger gives us some benefit regarding to knowledge sharing. However, there also disadvantages of using social messenger to support knowledge sharing process. Here, we identify the negative effects of using social messenger:

\section{Privacy and Security}

Some people do not want to be disturbed or share their personal information [13][16]. However, if they want to use social messenger, they have to share their personal information, such as email or phone number.

\section{Time Commitment}

Social messenger tend to be an addictive tool because they are not only used as communication tools but as entertainment tools such as sharing content [9]Elnasr et al., 2016). This feature makes users constantly replying, sharing, or chatting that makes users spend so much time at social messenger [5]. For students, this can disrupt their study because they are addicting into using social messenger [9].

\section{Digital Divide}

For some people that have an easy access to social messenger, they do not have problem to access it. However, some other people are fighting to get an access to internet or such application. So, social messenger can foster the digital divide among high-tech people and low-tech people [14].

\section{Ethical Issues}

Due to the high-frequency of communication and file sharing social messenger, ethical issue became significant challenges [4]. Plagiarism is one of example of the challenge of easy file sharing because users can easily share knowledge or file without legal copyright. 


\section{Disruptive from Real-World Social Relationship}

Social messenger creates a new virtual social relationship among its users that unfortunately, this makes users create less social relationship in the real-world [17]. Some people that spend much time in social media are possibly spend less quality time with their family, friend, or their environment [9].

\section{Conclusion}

In this modern era, social messenger plays important roles in knowledge sharing activities. The users can easily communicate and sharing using this technology. Social messenger support daily activities, such as communication, file, and content sharing, also it stimulate content creation. In knowledge sharing practice, social messenger can be used as discussion tools for tacit knowledge sharing and as file sharing to share explicit knowledge. However, there are some negative effect that may happen in using social messenger such as privacy and security concern, time commitment, digital divide, ethical issue, and disruptive real-world social relationship.

The implication of this study may contribute to academic area to give an explanation about how people use social messenger and the barrier of knowledge sharing practice in using this technology. The industry can also improve their features so the users can be facilitated to conduct a better knowledge sharing practice. This study is still in the early stage because the articles selected were limited. The future research (it can be empiric or theoretic) is possible to identify knowledge sharing practice using social messenger. This topic will become more interesting because social messenger is highly improved every time.

\section{Acknowledgement}

We would like to thank LPDP (Indonesia Endowment Fund for Education) of Ministry of Finance, Republic of Indonesia, for the financial support. We also please to acknowledge previous researchers or anyone who has helped with the paper at the end of the text.

\section{References}

[1] M. Oliveira, C. M. M. Curado, A. C. G. Maçada, and F. Nodari, "Using alternative scales to measure knowledge sharing behavior: Are there any differences ?," vol. 44, pp. 132-140, 2015.

[2] S. Ryan and R. V. O. Connor, "Acquiring and sharing tacit knowledge in software development teams: An empirical study," Inf. Softw. Technol., vol. 55, no. 9, pp. 1614-1624, 2013. https://doi.org/10.1016/j.infsof.2013.02.013

[3] H. Chumg, J. Seaton, L. Cooke, and W. Ding, "Factors affecting employees ' knowledge-sharing behaviour in the virtual organisation from the perspectives of well-being and organisational behaviour," Comput. Human Behav., vol. 64, pp. 432-448, 2016 https://doi.org/10.1016/j.chb.2016.07.011

[4] M. I. M. Eid and I. M. Al-jabri, "Social networking, knowledge sharing, and student learning: The case of university students," Comput. Educ., vol. 99, pp. 14-27, 2016

https://doi.org/10.1016/j.compedu.2016.04.007

[5] J. Lu, Q. Hao, and M. Jing, "Consuming, sharing, and creating content : How young students use new social media in and outside school," Comput. Human Behav., vol. 64, pp. 55-64, 2016. https://doi.org/10.1016/j.chb.2016.06.019

[6] M. Zahedi, M. Shahin, and M. Ali, "A systematic review of knowledge sharing challenges and practices in global software development," Int. J. Inf. Manage., vol. 36, no. 6, pp. 995-1019, 2016. https://doi.org/10.1016/j.ijinfomgt.2016.06.007

[7] ScienceDirect, "Elsevier's leading information solution," 2016. [Online]. Available: https://www.elsevier.com/solutions/sciencedirect. [Accessed: 21-Oct-2016].

[8] A.Sánchez-moya and O. Cruz-moya, "Whatsapp , textese , and moral panics : discourse features and habits across two generations," Procedia - Soc. Behav. Sci., vol. 173, pp. 300-306, 2015. https://doi.org/10.1016/j.sbspro.2015.02.069

[9] A.Dayani and S. Ariff, "Convenience or Nuisance?: The "WhatsApp' D ilemma," vol. 155, no. October, pp. 189196, 2014.

[10] H. G. M. Vossen and P. M. Valkenburg, "Do social media foster or curtail adolescents ' empathy? A longitudinal study," Comput. Human Behav., vol. 63, pp. 118-124, 2016.

https://doi.org/10.1016/j.chb.2016.05.040 
[11] M. Petruzzi and M. De Benedittis, "WhatsApp: a telemedicine platform for facilitating remote oral medicine consultation and improving clinical examinations," Oral Surgery, Oral Med. Oral Pathol. Oral Radiol., vol. 121, no. 3, pp. 248-254, 2016. https://doi.org/10.1016/j.oooo.2015.11.005

[12] J. Park and J. Lee, "Knowledge sharing in information systems development projects: Explicating the role of dependence and trust," JPMA, vol. 32, no. 1, pp. 153-165, 2014. https://doi.org/10.1016/j.ijproman.2013.02.004

[13] R. J. Raja-Yusof, A. A. Norman, S. S. Abdul-Rahman, N. Nazri, and Z. Mohd-Yusoff, "Cyber-volunteering: Social media affordances in fulfilling NGO social missions,” Comput. Human Behav., vol. 57, pp. 388-397, 2016. https://doi.org/10.1016/j.chb.2015.12.029

[14] S. Abdullah, "Exploring the Use and the Impacts of Social Media on Teaching and Learning Science in Saudi," Procedia - Soc. Behav. Sci., vol. 182, pp. 213-224, 2015. https://doi.org/10.1016/j.sbspro.2015.04.758

[15] N. Ain, R. Musa, and A. Azreen, "Social Media Intelligence Quotient ( SMIQ ) Among Graduates: Knowledge Gathering from Focus Group with Graduates," in Procedia - Economics and Finance, 2016, vol. 37, no. 16, pp. 304308.

[16] A.Elnasr, E. Sobaih, M. A. Moustafa, and P. Ghandforoush, "To use or not to use ? Social media in higher education in developing countries," Comput. Human Behav., vol. 58, pp. 296-305, 2016. https://doi.org/10.1016/j.chb.2016.01.002

[17] T. Kaya and H. Bicen, "The effects of social media on students ' behaviors; Facebook as a case study," Comput. Human Behav., vol. 59, pp. 374-379, 2016.

https://doi.org/10.1016/j.chb.2016.02.036

[18] W. He and L. Yang, "Using wikis in team collaboration: A media capability perspective," Inf. Manag., vol. 53, no. 7, pp. 846-856, 2016. https://doi.org/10.1016/j.im.2016.06.009

[19] M. Vaz and A. Lucas, "Knowledge sharing in project-based organizations : Overcoming the informational limbo," Int. J. Inf. Manage., vol. 34, no. 6, pp. 770-779, 2014. https://doi.org/10.1016/j.ijinfomgt.2014.07.003 